
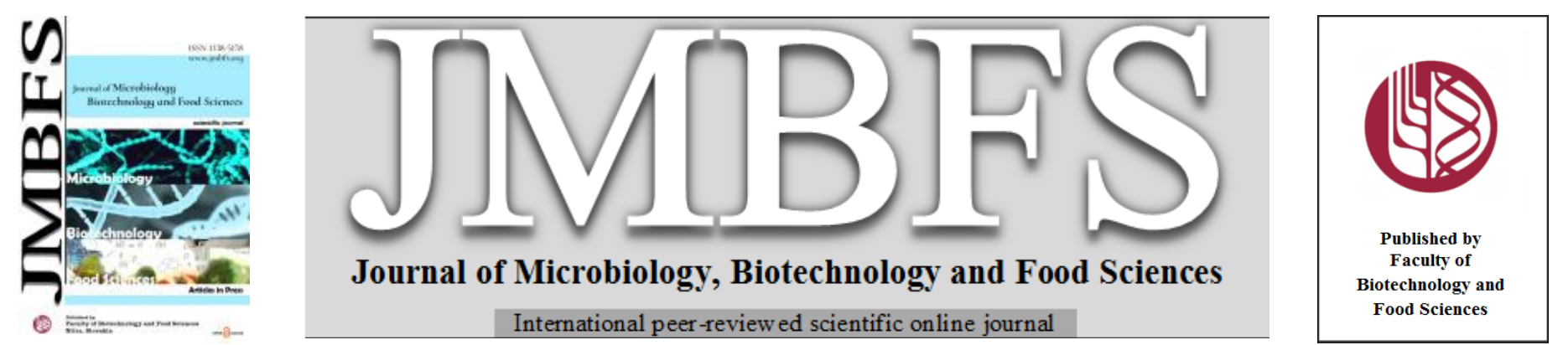

\title{
A REVIEW OF CURRENT KNOWLEDGE AND GAPS ABOUT CAMPYLOBACTER METHODS: FROM CULTURE TO CHARACTERIZATION
}

\author{
Aicha El Baaboua ${ }^{1,2}$, Mohamed El maadoudi ${ }^{2}$,Abdelhakim Bouyahya ${ }^{3, *}$, Ayoub Kounnoun ${ }^{2,4}$, Hajar Bougtaib ${ }^{2,4}$, Belmehdi Omarl, \\ Nadia Boujida ${ }^{l}$, and Jamal Abrini ${ }^{1}$
}

Address(es):

${ }^{1}$ Biology and Health Laboratory, Biotechnology and Applied Microbiology Team, Department of Biology, Faculty of Science, Abdelmalek-Essaadi University, Tetouan, Morocco.

${ }^{2}$ Regional Laboratory for Analysis and Research, National Office for Food Safety, Tangier, Morocco.

${ }^{3}$ Laboratory of Human Pathology Biology, Faculty of Sciences, and Genomic Center of Human Pathology, Mohammed V University, Rabat, Morocco.

${ }^{4}$ Laboratory of Applied Biology and Pathology, Department of Biology, Faculty of Science, Abdelmalek-Essaadi University, Tetouan, Morocco.

*Corresponding author: boyahyaa-90@ @otmail.fr

https://doi.org/10.55251/jmbfs.4154

\section{ARTICLE INFO}

Received 2. 1. 2021

Revised 17. 8. 2021

Accepted 2. 9. 2021

Published 1. 2. 2022

Regular article OPEN $\partial_{\text {AcCESS }}$

\begin{abstract}
Campylobacteriosis is a zoonotic disease caused by Campylobacter, mostly associated with consumption of contaminated foodstuffs and water. Campylobacter jejuni and Campylobacter coli recognized as the leader of foodborne diarrheal illness in humans. The frequency of these microorganisms in poultry is fairly high than Salmonella and more challenging to measure, which represent an expensive burden charge on public health due to their difficulties to master them, especially with the fast increase rates of multidrug-resistant of thermophilic Campylobacter strains. It is well recognized that Campylobacter spp. is a fastidious cell, difficult to isolate in laboratories owing to their requirements and sensibility. That's why; these factors must be taken into consideration during recovery protocols. A variety of phenotyping tests have been reported and widely used for confirmation and identification of Campylobacter species. Nonetheless, Whole Genome Sequencing (WGS) and Culture-Independent Diagnostic Tests (CIDTs) are new eras of hopeful technologies, mainly involved in the detection and characterization of threaten public health pathogens. This review aimed to describe the culture methods, phenotypic and genotypic schemes used to isolate, identify, and characterize Campylobacter isolates, through discussing the current knowledge and gaps related to the application of these techniques over others performed for typing this microaerophilic genus.
\end{abstract}

\section{INTRODUCTION}

C. jejuni subsp. jejuni and C. coli have been known as the most frequent bacteria, causing food borne gastroenteritis in humans around world, found in intestinal tract of many domestic animals, especially in birds (Keener et al., 2004; Escher et al., 2016; EFSA \& ECDC, 2016). The common food vehicles of Campylobacter are poultry meat, unpasteurized milk, and untreated water (Joensen et al., 2020).

The analysis of historical events in Campylobacter taxonomy showed the difficulties to recognize these species (Figure 1). Indeed, in 1886, Campylobacter was described by Escherich Theodor as spiral bacteria, but he failed to culture them by using standard methods (Kist, 1986). After that, many successive observations for the same shape have been reported in bovine abortion and sterility (Florent \& De Keyser, 1964; Skirrow, 2006), which was formerly classified as Vibrio fetus (Smith \& Taylor, 1919; Theobald Smith, 1919). These micro-organisms have continued to cause more infections in humans such as abortion, bacteremia, and diarrhea (Levy, 1946; Killam et al., 1966).

Because of their growth under a reduced oxygen tension and non-saccharolytic metabolism, these bacteria were separated from Vibrio group (Sebald and Veron, 1963). After their separation, many scientists have worked on the culture of Campylobacter (Sandstedt et al., 1983; Steele \& McDermott, 1984). Dekeyser et al. (1972) have described the first successful membrane filtration method for the recovery of Campylobacter from diarrheal stools. Moreover, further investigations have contributed in developing selective culture media and methods to identify and characterize these organisms (Khan et al., 2009; On, 2013; Li et al., 2018).

Campylobacter is biochemically inert and few phenotypic tests were established to distinguish these organisms from each other. As a result, it is extremely hard for practitioners to identify Campylobacter with such criteria (On, 2013; Duarte $\boldsymbol{e}$ al., 2016). Nowadays, the researchers in molecular biology field provide significant discoveries, aimed to facilitate diagnosis, control, and prevent outbreaks in public health system. The current molecular knowledge about foodborne bacteria offers fruitful outcomes.

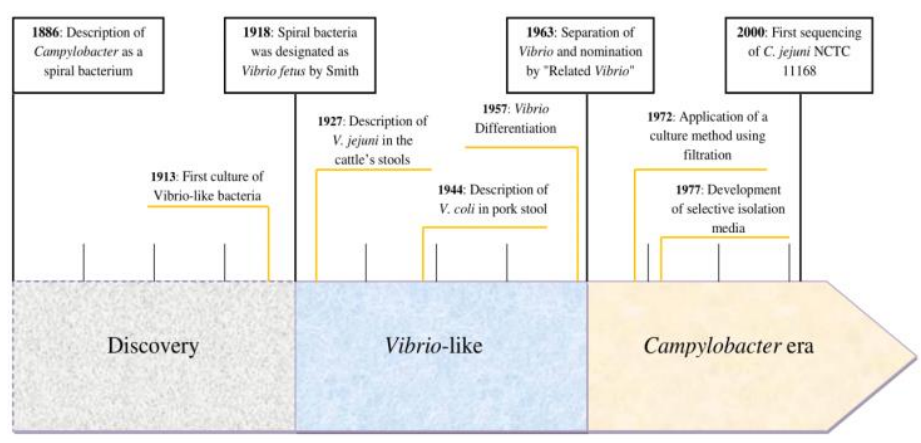

Figure 1 Historical events of Campylobacter taxonomy

For example, Whole Genome Sequencing (WGS) and Culture-Independent Diagnostic Tests (CIDTs) are new technologies intended to identify foodborne pathogens quickly and provide deep insights into their molecular mechanisms (Shea et al., 2017; Joensen et al., 2020). Due to the scarcity of literature reviews about efficient tools to master Campylobacter spp. from culture until characterization and in order to provide epidemiological information, this review aimed to discuss the following questions; What are the appropriate methods performed to culture Campylobacter? What are efficient phenotypic tests to identify these bacteria? What are the current techniques to characterize these pathogens? What offered WGS compared to Pulse Field Gel Electrophoresis 
(PFGE) and other molecular methods? How can the CIDTs help microbiologists to detect and control Campylobacter?

\section{CULTURE OF Campylobacter}

The bacterial culture aims to recover microorganisms and enhance their viability, through the use of specific culture media. The group of Campylobacter grow slowly (up to five days) even under optimal conditions (Butzler, 2004; Fitzgerald, 2015). Although their widespread, they are very sensitive to many environmental obstacles, where usually cells cannot survive, for example, in ambient oxygen for more than 18 hours (Garenaux et al., 2007; Hilbert et al., 2010).

\section{CULTURE MEDIA}

It has well recognized that the recovery of Campylobacter requires selective media, due to their inability to compete with other germs (Josefsen et al., 2003; Repérant et al., 2016). Today, there is a wide range of plating media, whose selectivity differs from each other's, and usually grouped in two categories; this includes blood-based agar (Preston, Skirrow, Butzler, Campy-cefex agar) and others based on charcoal instead of blood, such as Karmali and modified charcoal cefoperazone deoxycholate agar (mCCDA). The best recommendation for isolation are mCCDA and Karmali agar since Campylobacter colonies were easily recognized, despite their poor sensitivity and productivity, especially in food specimens (Chon et al., 2011). Additionally, many formulations of enrichment broths were made, whose Bolton broth and Preston's formula were the most used in culture methods before isolation step, when bacteria are injured or/and when the number of cells expected in samples is small (Bolton et al., 1983; Repérant et al., 2016). Overall, whether for enrichment or isolation of species, the Campylobacter culture media contains mainly the peptamin that provides amino acids (source of carbon), sulfide, and nitrogen required for making their energies, yeast extract provides B vitamins (coenzymes), and sodium chloride to maintain osmotic equilibrium. Campylobacter do not ferment carbohydrates (Epps et al., 2013); therefore etriphenyltetrazolium chloride was added to give contrasting color to colonies (Brown et al., 2013). Furthermore, defibrinated blood (horse or sheep), charcoals or other chemicals (e.g. ferrous sulfate, thioglycolate, and sodium metabisulfite or pyruvate) were inevitable in culture media formulas (Corry et al., 2003), owing to the fact that, during the respiratory chains, there is formation of toxic oxygen derivatives namely nitrite, nitric oxide, and peroxides sulfite (generating oxidative stress), harmful for Campylobacter cells, and therefore inhibit their growth (Baaboua et al., 2017). In contrast, some studies showed no significant differences in performance of enrichment broth supplemented or not with blood (Odongo et al., 2009; Gharst et al., 2013).

For facilitating the isolation of all Campylobacter species, the selective media incorporates antimicrobial agents intended to suppressed background competing bacteria, present in normal faecal flora, food or in environments (Chon et al., 2013; Kim et al., 2016). The Campylobacter culture media, whether used for isolation or enrichment, were typically supplemented with antibiotics mixture. For instance, cefoperazone, trimethoprim, and vancomycin inhibit Gram positive and/or negative aerobic and anaerobic bacteria, while amphotericin B and cycloheximide were incorporated to prevent yeasts and molds growth (Kumar et al., 2010). Nevertheless, other antimicrobial supplements like cephalothin, colistin and polymyxin B were also used, which may inhibit certain sensible strains of $C$. jejuni and $C$. coli, as well as other species that are less commonly encountered (i.e. $C$. upsaliensis, C. hyointestinalis, C. fetus) (Corry et al., 2003; Butzler, 2004) According to Li et al., (2018) findings, the selection of the suspected colonies on the selective medium becomes more and more difficult due to the increased of multidrug-resistant strains, which reduced the efficiency of isolation media and enrichment broth as well. These might be the reasons of why there have been such variations in Campylobacter prevalence reported worldwide (Biasi et al., 2011; Szczepanska et al., 2017; Es-soucratti et al., 2020)

Chromogenic media were largely described for the recovery of Campylobacter in multiple samples (food, water, and in particular in clinical samples), based on the use of chromogenic substrate specific and selective for desired organism (Perry and Freydière, 2007). CASA, Campy Food, and CHROM agar are some examples of Campylobacter chromogenic media, provided by BioMerieux, whose aimed to reduce time and cost of analysis by facilitating the recognition of presumptive colonies of Campylobacter visually and subsequently avoiding subculture and confirmatory tests (Al-Wasify, 2013). Conversely, the bacterial detection was limited in one or two species, matter that limit their sensitivity compared to traditional media. Likewise, the chromogenic formulas incorporate antimicrobial molecules that can prevent the recovery of damaged cells, hence, the combination of an enrichment step remains required beforehand (Malhotra-Kumar et al., 2010).

\section{INCUBATION CONDITIONS}

These bacteria are microaerobic since they require an atmosphere depleted of oxygen. Many investigations have declaimed that $10 \%$ of carbon dioxide $\left(\mathrm{CO}_{2}\right)$ $5 \%$ dioxygen $\left(\mathrm{O}_{2}\right)$, and $85 \%$ of nitrogen $\left(\mathrm{N}_{2}\right)$ was the favorable gas mixture needed during incubation period of Campylobacter spp. (Keener et al., 2004; Macé et al., 2015). For that, and after the development of jars containers, several microaerophilic atmosphere generation systems were described (Haines $\boldsymbol{e t}$ al., 2011) particularly, candle jar, chemical substances (Copper sulfate and sodium bicarbonate), gas generating envelopes, and tri-Gas $\mathrm{CO}_{2}$ incubator (Table 1). First, candle supplies a microaeophilic environment, nearly to $17-19 \% \mathrm{O}_{2}$ and $2-4 \%$ $\mathrm{CO}_{2}$ appropriated for the isolation of Campylobacter. However, this system offer some advantages that are limited only in cost and simplicity (Luechtefeld $\boldsymbol{e t}$ al., 1982; Hilbert et al., 2010). Moreover, Wang and others (1982) were demonstrated that the increase in bacteria density in jars, only at $42{ }^{\circ} \mathrm{C}$, decreases the oxygen tension, and consequently enhance the growth of $C$. jejuni strains Secondly, the commercially available gas generating envelopes were used in bags and jars to provide the optimal microaerophilic atmosphere $\left(5 \% \mathrm{O}_{2}, 10 \% \mathrm{CO}_{2}, 85 \%\right.$ $\mathrm{N}_{2}$ ) for a best growth of C. jejuni compared to candle jar (Wang et al., 1982). Other than cost, the limited numbers of incubated Petri dishes were the main described disadvantages of this system. Finally, and to overcome the inconvenience of gas generating envelopes, tri-Gas $\mathrm{CO}_{2}$ incubator was invented to supply similar microaerophilic atmosphere conditions as the gas generating envelopes and also accommodate large number of Petri dishes, for a suitable routine use in laboratories (Davis and DiRita, 2008).

Campylobacter requires favorable temperatures for growth. The incubation usually carried out at $37^{\circ} \mathrm{C}$ or $42^{\circ} \mathrm{C}$, but it is very common, for routine diagnosis practice, to incubate at $42^{\circ} \mathrm{C}$ to minimize the growth of contaminants and select the frequen thermo-tolerant species (Silva et al., 2011). Indeed, $C$. jejuni includes two subspecies $C$. jejuni subsp. jejuni and $C$. jejuni subsp. doylei, where subspecies jejuni are more frequent than subspecies doylei due to the fact that the temperature of incubation used during culture method is often $42{ }^{\circ} \mathrm{C}$ (Miller et al., 2007; Parker et al., 2007). In addition, other species of Campylobacter (e.g. C. helveticus, C. fetus, and C. hyoinestinalis) grow better at $37^{\circ} \mathrm{C}$ (Corry et al., 1995; Macé et al., 2015).

Table 1 Comparison of three microaerophilic atmosphere generation systems

\begin{tabular}{|c|c|c|c|}
\hline System & Advantages & Disadvantages & References \\
\hline $\begin{array}{l}\text { Candle jar } \\
\left(17-19 \% \mathrm{O}_{2}, 2-4 \%\right. \\
\left.\mathrm{CO}_{2}\right)\end{array}$ & $\begin{array}{l}\text { Simple, } \\
\text { inexpensive }\end{array}$ & $\begin{array}{l}\text { Cannot produce } \\
\text { optimum } \\
\text { microaerophilic } \\
\text { condition, } \\
\text { Cannot detect } C \text {. } \\
\text { jejuni at } 37^{\circ} \mathrm{C}\end{array}$ & $\begin{array}{l}\text { (Wang et al., } \\
\text { 1983; Hilbert } \\
\text { et al., 2010) }\end{array}$ \\
\hline $\begin{array}{l}\text { Gas generating } \\
\text { envelopes } \\
\left(5 \% \mathrm{O}_{2}, 10 \% \mathrm{CO}_{2} \text {, }\right. \\
\left.85 \% \mathrm{~N}_{2}\right)\end{array}$ & $\begin{array}{c}\text { Simple, large } \\
\text { size of } \\
\text { colonies }\end{array}$ & $\begin{array}{c}\text { Expensive, } \\
\text { Number of plates } \\
\text { incubated were } \\
\text { limited }\end{array}$ & $\begin{array}{l}\text { (Wang et al., } \\
\text { 1982) }\end{array}$ \\
\hline $\begin{array}{l}\text { Tri-Gas } \mathrm{CO}_{2} \\
\text { incubator } \\
\left(5 \% \mathrm{O}_{2}, 10 \% \mathrm{CO}_{2} \text {, }\right. \\
\left.85 \% \mathrm{~N}_{2}\right)\end{array}$ & $\begin{array}{l}\text { Reliable, } \\
\text { productive }\end{array}$ & Expensive & $\begin{array}{l}\text { (Davis and } \\
\text { DiRita, 2008) }\end{array}$ \\
\hline
\end{tabular}

\section{CULTURE METHODS}

As other pathogenic micro-organisms, many culture methods were reported to isolate Campylobacter strains from three distinct sources (Food, stools, and water specimens). The protocol of standard method ISO 10272-1, membrane filtration (Khan et al., 2009), and centrifugation method (FDA, 2020) were based on samples preparation, enrichment, and isolation stage (Table 2). Overall, through the observation of these protocols, it seems that the three methods have similar incubation conditions (Period and temperature), formulations of enrichment medium (Bolton broth), as well as culture media used for isolation of Campylobacter genus. However, the preparation stage was the only difference, in which Campylobacter was concentrated using centrifugation or membrane filtration, but not in the case of standard method ISO 10272-1. Li et al. (2018) have indicated that the enrichment with filtration method was the most effective culture method for Campylobacter genus from the diarrheal stool samples. Likewise, in their comparative study between centrifugation (CF) and membrane filtration (MF) method for isolation and detection of thermophilic Campylobacter in agricultural watersheds, Khan et al. (2009) have found that both methods detected similar frequency occurrence of $C$. jejuni. Nonetheless, the CF method detected significantly higher frequencies of C. coli $(17 \%)$ and other Campylobacter species (13\%) compared to the MF method (11\% and 3\%, respectively). Based on their results, it has been showed that the recovery effectiveness of Campylobacter species depend on culture method used, caution that must be taken into consideration when comparing studies that report on the occurrence of Campylobacter at the genus level (Khan et al., 2009). 
Table 2 Description of three Campylobacter spp. culture methods, according to standard method ISO 10272-1, NARMSMethodology (Medicine, 2020) and Khan et al., (2009). 1: Sample's preparation, 2: Enrichment, and 3: Isolation. A: Charcoal agars (Karmali and mCCDA) and B: Blood-based agars (Preston, Skirrow, Butzler, Campy-cefex agar).

(1)

Recently, the qualitative detection method of Campylobacter spp. ISO 10272-1: 2017 was amended and adapted according to resistance rates against $\beta$-lactams antibiotics of third generation, used in selective culture media, and because of nonefficiency of one culture method for the recovery of these species (Acke $\boldsymbol{e t}$ al., 2009; Griggs et al., 2009; Casagrande Proietti et al., 2020). In 2019, seventeen laboratories from 13 different countries in Europe have participated in interlaboratory study of validation of the three procedures described in the revised standard method ISO 10272-1:2017. They concluded that the revised procedures of standard method were satisfactory for the detection of Campylobacter in different matrices. However, the values of $\mathrm{LOD}_{50}$ derived from this interlaboratory study may not be applicable to food type or strains other than the ones carried out in the study (Biesta-Peters et al., 2019). So that, each monitoring laboratory must validate appropriate culture method according to the samples analyzed for a future surveillance program.

\section{IDENTIFICATION AND CHARACTERIZATION METHODS}

In order to control the risks associated with prevalence, transmission mode, and resistance, the identification and characterization of these species provide very useful information. To our knowledge, there is no accepted standard scheme to process the identification and characterization of Campylobacter (Hiett, 2017) (Figure 2).

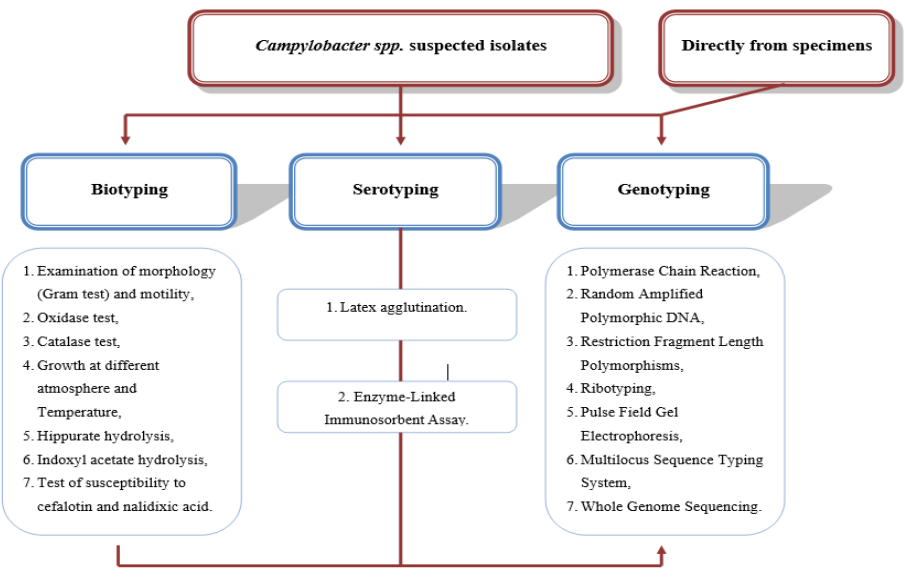

Figure 2 Identification and characterization methods for Campylobacter spp.

\section{BIOTYPING}

According to the traditional school, the first confirmation stage consists to distinguish the characteristic colonies of Campylobacter present on the isolation media, which usually appears after 24 to 72 hours (Rahimi et al., 2010; Szczepanska et al., 2017). On charcoal agar plates, the characteristic colonies were greyish to white with a metallic sheen, round, high, convex, smooth, shiny, and moistened with a regular edge (Figure 3). On blood agar plates, Campylobacter colonies are slightly pink, round, convex, smooth, and shiny with a regular edge. After the recognition and purification of suspected colonies of Campylobacter on blood base agar (oftenly Columbia base supplemented with $5 \%$ of defibrinated horse blood), a microscopic examination for morphology (Gram staining), motility, oxidase, catalase test, and growth under different conditions of suspicious colonies of Campylobacter were the most acceptable techniques reported in biotyping scheme in order to confirm the genus (Duarte et al., 2016). Moreover, the susceptibility against cefalotin and nalidixic acid, indoxyl acetate, and hippurate hydrolysis were recommended in standard method ISO 10272-1 to identify Campylobacter species (Colles et al., 2010; Singh, et al., 2011). Other studies have suggested complimentary biochemical methods such as $\mathrm{H}_{2} \mathrm{~S}$ production in triple sugar iron medium, growth in $\mathrm{NaCl} 3.5 \%$, growth in glycine $1 \%$, growth on MacConkey agar, growth on nutrient agar, and nitrate reduction (Kiehlbauch $\boldsymbol{e t}$ al., 1991; Silva \& Van Dender, 2013; Silva et al., 2020). The hippurate hydrolysis was reported as the only biochemical criterion that can differentiate $C$. jejuni from other species (Adzitey and Corry, 2011), while other scientists found that hippurate hydrolysis test gives false positive and negative results (Nakari et al., 2008). Today, the test of sensitivity to nalidixic acid recommended by standard method ISO 10272-1 should be revised due to the increase of resistant isolate to nalidixic acid in C. jejuni and C. coli (Biasi et al., 2011; Vinueza-Burgos et al., 2017).

For a long time, Campylobacter has been confused with group of bacteria named related organisms (On, 2001; Lastovica et al., 2014). In this regard, several studies have cited critical biochemical tests to differentiate Campylobacter genus from Helicobacter and Arcobacter (Table 3). In the light of previously demonstrated finding on growth temperature, Vandamme and collaborators (1991) showed that Campylobacter cannot grow at $25^{\circ} \mathrm{C}$ compared to Helicobacter that cannot grow at $42{ }^{\circ} \mathrm{C}$ and Arcobacter that grown at 15 to $25^{\circ} \mathrm{C}$. Except $C$. lari, all other species of Campylobacter are unable to metabolize urea, contrary to Arcobacter and Helicobacter.

The shortcomings associated with biochemical identification scheme were usually noted in discriminatory power that is only limited to the known species of Campylobacter and also time consuming (On, 1996; Ugarte-Ruiz et al., 2013). The API Campy strip (BioMérieux, Marcy l'Etoile, France) is miniaturized gallery which contains eleven conventional tests and nine inhibition tests. It was developed to save space and time of materials preparation, so the results were obtained more rapidly, and without forgetting to mention the eliminated risk linked to improper sterilization and preparation of media during the use of classic biochemical 
methods (Huysmans et al., 1995; Martiny et al., 2011). Despite the clear advantages of API Campy, this approach is not ideal. Firstly, the inappropriate concentration of bacteria may give false results. Secondly, the misidentifications of species and lack of certain strains in identification key of API Campy have been proved (Reina et al., 1995; On, 1996). This means that further investigations are required to continue to use this kit.

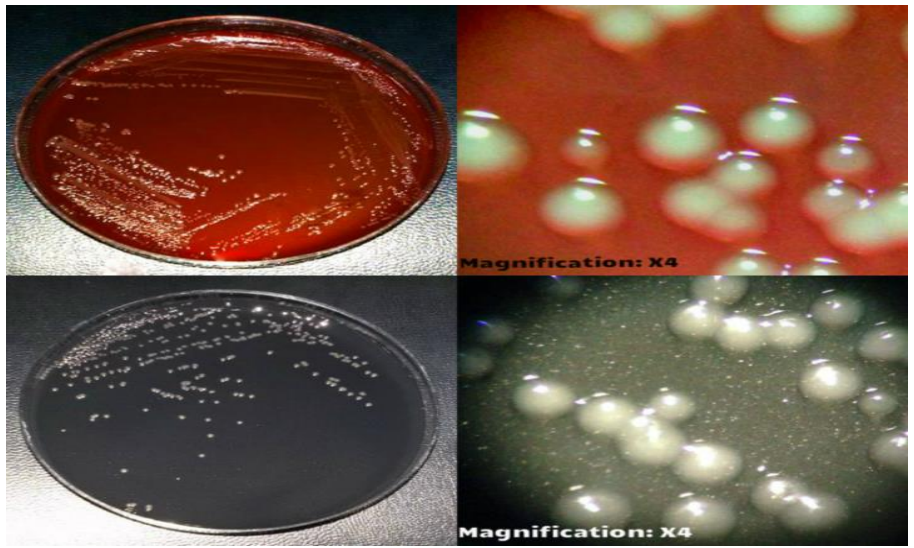

Figure 3 Characteristic colonies of $C$. jejuni on Campylobacter Blood Agar Medium (red medium) and on Campylobacter Blood Free Medium (black medium). These pictures were taken in regional laboratory of analysis and research of Tangier, Morocco.

\begin{tabular}{|c|c|c|c|c|}
\hline Test & Campylobacter & Helicobacter & Arcobacter & References \\
\hline Growth temperature & Not at $25^{\circ} \mathrm{C}$ & Not at $42{ }^{\circ} \mathrm{C}$ & $\begin{array}{l}\text { Growth at } 15^{\circ} \mathrm{C} \\
\text { and } 25^{\circ} \mathrm{C}\end{array}$ & (Vandamme et al., 1991) \\
\hline Urea degradation & $\begin{array}{l}\text { + Only } C \text {. lari biovar } \\
\text { VPTC }\end{array}$ & + & + & $\begin{array}{l}\text { (Marshall et al., 1990; } \\
\text { Miller } \text { et al., 2007) }\end{array}$ \\
\hline
\end{tabular}

+ : positive

\section{SEROTYPING}

Serological tests have been performed for long time in clinical diagnostic and epidemiological studies to define the prevalence of serotype related to disease. All serologic techniques have in common, antibody or antigen detection. The extraintestinal invasion of $C$. jejuni pathogenesis mechanism can cause bacteremia. In that case, and in order to protect its entity, the body produces specific antibodies against $C$. jejuni (O'Hara et al., 2017; Pacanowski et al., 2008). Thus, numerous rapid immunological methods have been developed, namely latex agglutination, Enzyme-Linked Immunosorbent Assay and others (Tuuminen et al., 2013) Latex agglutination tests are one of the easiest serological tests, which help in determination of the presence or absence of specific surface antigens. The reaction is based on the detection of target strain clumping particles with polyclonal or specific antibodies of the bacterial membrane or of the flagellum. For this purpose, several kits have been evolved following two schemes (Frost et al., 1998; Woodward \& Rodgers, 2002). The Penner and Hennessy scheme, established in 1980, uses thermostable antigens highly immunogenic, essentially lipopolysaccharide (LPS) of the outer membrane, flagellum (AGH), or capsule (AGK). The Lior scheme, founded in 1982, corresponds to thermolabile antigens of lipopolysaccharide nature (LPS/AgO), but also comprises certain components of the cytoplasm and proteins of the outer membrane. The agglutination latex test is carried out after culturing bacteria, which encumber up time. Likewise, the kit is not available for all Campylobacter species (Nachamkin and Barbagallo, 1990) Other than auto-agglutination of $C$. jejuni isolates, it has been also recognized that C. jejuni and C. coli failed to agglutinate because of flagellin glycosylation phenomenon, the facts that limit latex agglutination uses (Guerry et al., 2006). Enzyme-Linked Immunosorbent Assay (ELISA) is an immunological method aimed to visualize the antigen-antibody reaction of target microorganisms. The presence of antigen was indicated by color change of chemical substrate. ELISA test can cost-effectively shorten the time for analysis by screening out presumptive positives specimens in less than 24 hours (Quetz et al., 2010; Turonova et al., 2015). In fact, many authors have been reported the high sensitivity and specificity of antigen selection, which have been successfully used in serodiagnosis of Campylobacter infections (Hum et al., 1991; Quetz et al., 2010). Another advantage that ELISA offers is the capacity of differentiating between nonexposure, chronic exposure, and recent exposure to $C$. jejuni antigens. Both ELISA and latex agglutination tests, are particularly important for the presumptive identification in case of suspicious post-infection or in case of complications cause by $C$. fetus and $C$. jejuni (Guillain-Barré syndrome, reactive arthritis, and bacteraemic), especially in immunocompromised individuals (Ang et al., 2007).

\section{GENOTYPING}

Molecular biology have been widely improved worldwide to overcome the inconveniences of biotyping and serological tests (e.g. time, reliability, limited selectivity, and cost-effectiveness) (Alves et al., 2016; Gosselin-Théberge et al.,
2016). These methods are based on nucleic acid detection and genes characterization that confer mobility, adhesion, invasion, toxin production, resistance and others. The most relevant genotyping methods reported for characterization of Campylobacter are Polymerase Chain Reaction (PCR), Restriction Fragment Length Polymorphism (RFLP), PFGE, MLST, and WGS (Table 4) (Leblanc-Maridor et al., 2011).

Table 4 Main methods used for characterization of Campylobacter isolates

\begin{tabular}{|c|c|c|c|}
\hline Methods & Advantages & Limitations & References \\
\hline $\mathrm{PCR}^{1}$ & $\begin{array}{l}\text { Quick, easy and } \\
\text { high sensitivity. }\end{array}$ & $\begin{array}{l}\text { Cost and } \\
\text { inhibitors, } \\
\text { Cannot } \\
\text { distinguish } \\
\text { between VBNC } \\
\text { and viable cells. }\end{array}$ & (Law et al., 2015) \\
\hline RFLP $^{2}$ & $\begin{array}{l}\text { Discriminatory, } \\
\text { Identification of } \\
\text { new species. }\end{array}$ & $\begin{array}{l}\text { and viable cells. } \\
\text { Laborious and } \\
\text { time-consuming } \\
\text { process. }\end{array}$ & (Botstein et al., 1980) \\
\hline $\mathrm{PFGE}^{3}$ & $\begin{array}{l}\text { Provide } \\
\text { meaningful } \\
\text { evolutionary } \\
\text { analyzes, } \\
\text { Discriminate } \\
\text { between outbreak } \\
\text { associated and } \\
\text { sporadic strains }\end{array}$ & $\begin{array}{l}\text { Cost and } \\
\text { reproducibility, } \\
\text { Need } \\
\text { bioinformatics } \\
\text { analysis for } \\
\text { interpretation. }\end{array}$ & (Goering, 2010) \\
\hline MLST $^{4}$ & $\begin{array}{l}\text { Discrimination } \\
\text { and } \\
\text { reproducibility, } \\
\text { Easy for } \\
\text { comparison of } \\
\text { nucleotide } \\
\text { sequence-based. }\end{array}$ & Cost and labour. & (Dingle et al., 2008) \\
\hline $\mathrm{WGS}^{5}$ & $\begin{array}{l}\text { High } \\
\text { discriminatory } \\
\text { power, } \\
\text { Evolutionary } \\
\text { understanding. }\end{array}$ & Cost and speed. & $\begin{array}{l}\text { (Lindsey et al., 2016; } \\
\text { Llarena et al., 2017) }\end{array}$ \\
\hline
\end{tabular}
field gel electrophoresis; ${ }^{4}$ Multilocus fragment length polymorphism; ${ }^{5}$ Pused Sequencing.

The PCR innovative types (Conventional, qPCR, multiplex, and others) have been largely known for their high sensitivity, ease of operation, and fast results (Garibyan and Avashia, 2013). In fact, the specific 16S rRNA gene was described 
to confirm Campylobacter genus, while hipO, CadF, CeuE, mapA genes and other specific-genes were reported to identify Campylobacter species (Ghorbanalizadgan et al., 2014; Begum et al., 2015; Ricke et al., 2019). PCR methods can be used directly (Enriched samples and suspected isolates), or in a combination with biochemical tests for further reliability and speed (Taboada et al., 2013; Efimochkina et al., 2019). Despite the aforementioned advantages, PCR has many disadvantages such as capacity to detect the DNA of dead bacteria, viable but non-cultivable strains, and the limited number of microorganisms detected in reaction (Liang et al., 2018). Further, the presence of lysed blood in Campylobacter enrichment broths may inhibit the amplification (Law et al., 2014).

Ribotyping refers to the first process describing the specific recognition between labeled $16 \mathrm{~S}, 23 \mathrm{~S}$, or $5 \mathrm{~S}$ ribosomal RNA (rRNA) gene probes and digested genomic DNA by single endonuclease (Wassenaar and Newell, 2000). The generated ribotypic sequences reflect the diversity of rRNA operons present in a bacteria species (Bouchet $\boldsymbol{e t}$ al., 2008). Indeed, the name of this technique was amended according to the polymorphism observed in rRNA analyzed of species and was, lately, recognized by RFLP. Briefly, this molecular marker method is based on fragmentation of DNA with one or more of restriction enzymes and then the fragments are separated by electrophoresis, blotted onto a membrane, and hybridized, or exposed to a labeled probe of rRNA for visualization. The first application of RFLPs analysis on polymorphic sites of evolution of rRNA genes, have revealed that polymorphisms were within chromosomal genes (Bouchet $\boldsymbol{e}$ al., 2008). Moreover, the characterization of Campylobacter flaA gene by RFLP was appeared to be suitable as a preliminary typing method based on ease of manipulation, equipment availability, and cost compared to MLST, PFGE (O'reilly et al., 2006; Vinueza-Burgos et al., 2017). Nowadays, this technology has been combined with PCR for studying deeper the diversity of specific genes. By applying PCR-RFLP, Yadav et al., (2018) compared three different restriction endonucleases (DdeI, HinfI and DpnII) to analyze the flagellin gene polymorphism of $C$. jejuni isolates and have determined that DdeI yielded high polygenic pattern ( 15 clusters) comparable to DpnII (7 clusters) and HinfI (6 clusters).

Pulsed-field gel electrophoresis is a variety of RFLP that consists to separate large fragments of genomic DNA, generated from enzymatic digestion of DNA (up to $10 \mathrm{Mb}$ ) (Sabat et al., 2013). PulseNet surveillance systems is a global network laboratories of public health, aim to monitor foodborne illnesses detected in human outbreak and control new hazardous cases (Fontanot et al., 2014). Indeed, PulseNet uses PFGE to subtype foodborne pathogens isolates with the high discriminatory power to differentiate clustered cases of campylobacteriosis sporadic disease and outbreak occurring in the community and to characterize isolates from their environment (Bakhshi et al., 2016; Di Giannatale et al., 2019). Annually, this system prevents an estimated 270,000 illnesses and saves more than $\$ 500$ million in medical costs and lost productivity (Scharff et al., 2016).

After the development of first generation of sequencing technology by Sanger and Coulson in 1975, a variety of sequencing techniques have been described (Sanger and Coulson, 1975). For instance, MLST is based on DNA sequencing of seven conserved housekeeping genes (Dadar et al., 2018; Aksomaitiene et al., 2019). This technology represents a valuable understanding of the variability and relationship of Campylobacter isolated from outbreaks cases or food. Therefore, the sequence types can be shared between laboratories worldwide (Lytsy et al., 2017). Dingle et al., (2008) have emphasized the easy comparison of nucleotide sequence-based for MLST method, a good discrimination, and reproducibility power.

Whole genome sequencing (WGS) is new sequencing generation for analyzing the entire genome of pathogenic bacteria and thus improves our knowledge in evolutionary biology as well as makes clinical progress easy. This genome analysis method gives very precise and more detailed information about bacteria compared to old methods (i.e., MLST and PFGE), and generating stable data, easy to share and compare at the international level (Lytsy et al., 2017). Many researchers suggested that the integration of genome sequencing in routine public health surveillance of $C$. jejuni, would facilitate the identification of possible case clusters, which should allow the implementation of more effective intervention strategies in prevention and control of campylobacteriosis cases (Ghatak et al., 2017; Llarena et al., 2017). For these reasons, Centers for Disease Control and Prevention (CDC) are proceeding to develop analysis, to validate, and to establish a standardized procedure to make it easier for network members to exchange and compare data, within laboratory networks that support foodborne disease surveillance and outbreak. Indeed, the standardization of such data across laboratories, for routine surveillance, will provide deep understanding about outbreak identification, source attribution, antimicrobial resistance, serotype, and virulence factors that can be extracted at the same time (Ellington et al., 2017; Ghatak et al., 2017). Regardless of these existing highlighted advantages, aforementioned, the adoption of whole genome sequencing in clinical laboratories remain challenging because of culture dependent, limited speed, and very highcost. Another significant challenge is the lack of systematic surveillance of Campylobacter, as well as the significant resources required to set up for routine analysis, which may limit the success of this approach (Joensen et al., 2020).

\section{CULTURE-INDEPENDENT DIAGNOSTIC TESTS}

Culture-independent diagnostic tests (CIDTs) are an alternative technology based on molecular applications such as ELISA and PCR, intended to offer rapid results as compared to standard microbiological culture (Imdad et al., 2018). These tests can screen or/and identify disease-causing foodborne illnesses quickly, without need to culture bacteria in laboratory. Hospitals use this new technology because they are less labor-intensive and provide faster results than culture methods (Singh et al., 2011). Moreover, some CIDTs are able to detect more than single pathogen simultaneously, within hours, which results in faster public health action and prevention, compared to the days using traditional culture techniques (Janda and Abbott, 2014; Shea et al., 2017). These tests can improve the speed of diagnosis but may limit the ability to survey outbreaks (Langley et al., 2015). In reality, laboratories need isolated strains in order to provide further characterization via PFGE, WGS, and susceptibility tests against antimicrobial molecules. By skipping the step of producing a bacterial isolate, many consequences will be faced. For example, DNA fingerprints produced by PFGE won't be able to continue detecting clusters and such valuable opportunities for improving the food safety and emerging pathogens will be lost. Moreover, the information gathered about antibiotic resistance will not be available and no antibiotics resistance state will be known. As results, it will be difficult to treat disease and monitor resistance trends over time (Couturier, 2016; Marder et al., 2017; McAdam, 2017). Whenever the clinical laboratories embrace these new culture-independent diagnostic tests, the challenge increase to more study and harmonize this available technology for public health.

Owing to the increased use of CIDTs by clinicians and public health practitioners, the authorities takes advantages of this and try to accommodate these new technological tests not only to speed up the microbes screening but also prompting thorough outbreak detection in emerging infections program surveillance (Couturier, 2016). In this context, CDC is encouraging clinics and hospitals to use them as primarily test and then send positive clinical specimens to the state health laboratory for pathogen isolation by culture (Marder et al., 2017; McAdam, 2017). Nonetheless, the approach of sending clinical specimens to another laboratory after they get a diagnosis using CIDTs has added additional challenges, including receiving CIDTs reports from hospitals, the potential loss of pathogen viability during transport, setting case during outbreaks, communicating CIDTspositive results with patients, and interpreting results that are positive for multiple pathogens (Atkinson et al., 2013). As a result, these concerns should be balanced carefully against the said advantages.

\section{CONCLUDING REMARKS AND PERSPECTIVES}

A standard method for future surveillance systems is crucial to any monitoring laboratory. For that fact, the present review aimed to discuss the current knowledge and challenges of culture, identification, and characterization methods of Campylobacter species. Apparently, the selection of the appropriate methods is not always easy; owing to the different levels of discriminatory power, purpose, as well as the data needed to interpret. The classical biotyping have been described useful for preliminary surveillance and simple to perform, despite the fact that, they are heavy and labor. Also, there is possibility of providing false negative results due to transformation of viable but non-culturable state under unfavorable conditions. Furthermore, the identification of Campylobacter species has always been difficult using phenotypic methods, owing to their low metabolic activity and timeconsuming. Nevertheless, molecular methods come to exceed these limitations and provide more beneficial techniques. Such advanced tests are extremely useful to clinicians, especially, PFGE and MLST that have been contributed to the current knowledge on $C$. jejuni outbreaks in human. The recent evidence suggests that whole genome sequencing is the most likely method to be used routinely in C. jejuni isolates for the detection and investigation of outbreaks. This new technology reveals crucial insights on various aspects of biology and epidemiology of these important pathogens, including, antimicrobial resistance, serotype and virulence factors traits.

For now, these innovations are in the early stages of development and could need more implementation work for sustainable use, thus we invite researchers to carry out studies regarding culture methods as fundamental processor to get deep insights into their metabolic mechanisms and therefore to speed up the growth phenomena of these strains as well as better understanding of their biochemical profiles. Also, the aspect of molecular identification techniques of Campylobacter species needs further studies to learn more about neglected species and to avoid false results that may be occurs during this operation.

\section{COMPETING INTERESTS}

All authors have declared no competing interests exist. 


\section{REFERENCE}

Acke, E., McGill, K., Golden, O., Jones, B. R., Fanning, S., \& Whyte, P. (2009). A comparison of different culture methods for the recovery of Campylobacter species from pets. Zoonoses Public Health., 56, 490-495. https://doi.org/10.1111/j.18632378.2008.01205.x.

Adzitey, F., and Corry, J. (2011). A Comparison between Hippurate Hydrolysis and Multiplex PCR for Differentiating Campylobacter coli and Campylobacter jejuni. Trop. Life Sci., Res. 22, 91-98. https://www.ncbi.nlm.nih.gov/pubmed/24575212 Aksomaitiene, J., Ramonaite, S., Tamuleviciene, E., Novoslavskij, A., Alter, T., \& Malakauskas, M. (2019). Overlap of Antibiotic Resistant Campylobacter jejuni MLST Genotypes Isolated From Humans, Broiler Products, Dairy Cattle and Wild Birds in Lithuania. Front. Microbiol., 10 . https://doi.org/10.3389/fmicb.2019.01377.

Alves, J., Hirooka, E. Y., \& Oliveira, T. C. R. M. de (2016). Development of a multiplex real-time PCR assay with an internal amplification control for the detection of Campylobacter spp. and Salmonella spp. in chicken meat. LWT-Food Sci. Technol., 72, 175-181. https://doi.org/10.1016/j.lwt.2016.04.051.

Al-Wasify, R. S. (2013). Sensitivity \& Specificity of Chromogenic Media for Detection of some Pathogens in Water. Int. J. Environ. Sustain., 2. https://doi.org/10.24102/IJES.V2I1.157

Ang, C. W., Krogfelt, K., Herbrink, P., Keijser, J., van Pelt, W., Dalby, T., et al. (2007). Validation of an ELISA for the diagnosis of recent Campylobacter infections in Guillain-Barré and reactive arthritis patients. Clin. Microbiol. Infect., 13, 915-922. https://doi.org/10.1111/j.1469-0691.2007.01765.x.

Atkinson, R., Maguire, H., \& Gerner-Smidt, P. (2013). A Challenge and an Opportunity To Improve Patient Management and Public Health Surveillance for Food-Borne Infections through Culture-Independent Diagnostics. J. Clin. Microbiol., 51, 2479-2482. https://doi.org/10.1128/JCM.00253-13.

Baaboua, A. E., Maadoudi, M. E., Bouyahya, A., \& Abrini, J. (2017). Intestinal Infections of Campylobacter: A Review. Microbiol. Res. J. Int., 18, 1-8. DOI 10.9734/MRJI/2017/31496

Bakhshi, B., Kalantar, M., Rastegar-Lari, A., \& Fallah, F. (2016). PFGE genotyping and molecular characterization of Campylobacter spp. isolated from chicken meat. Iran. J. Vet. Res., 17, 177-183. http://www.ncbi.nlm.nih.gov/pmc/articles/pmc5090151/

Begum, S., Sekar, M., Gunaseelan, L., Gawande, M., Suganya, G., Malar, P. A. S., et al. (2015). Molecular identification of Campylobacter jejuni and coli from chicken, calves and dogs to determine its potential threat on human being. Vet World., 8, 1420-1423. https://doi.org/10.14202/vetworld.2015.1420-1423

Biasi, R. S., Freitas de Macedo, R. E., Scaranello Malaquias, M. A., \& Franchin, P. R. (2011). Prevalence, strain identification and antimicrobial resistance of Campylobacter spp. isolated from slaughtered pig carcasses in Brazil. Food Control., 22, 702-707. https://doi.org/10.1016/j.foodcont.2010.10.005.

Biesta-Peters, E. G., Jongenburger, I., de Boer, E., \& Jacobs-Reitsma, W. F. (2019) Validation by interlaboratory trials of EN ISO 10272 - Microbiology of the food chain - Horizontal method for detection and enumeration of Campylobacter spp. Part 1: Detection method. Int. J. Food Microbiol., 288, 39-46. https://doi.org/10.1016/j.ijfoodmicro.2018.05.007.

Bolton, F., Coates, D., Hinchliffe, P., \& Robertson, L. (1983). Comparison of selective media for isolation of Campylobacter jejuni/coli. J. Clin. Pathol., 36, 78 83. https://dx.doi.org/10.1136\%2Fjcp.36.1.78.

Botstein, D., White, R. L., Skolnick, M., \& Davis, R. W. (1980). Construction of a genetic linkage map in man using restriction fragment length polymorphisms. Am J. Hum. Genet., 32, 314-331. https://www.ncbi.nlm.nih.gov/pubmed/6247908

Bouchet, V., Huot, H., \& Goldstein, R. (2008). Molecular Genetic Basis of Ribotyping. Clin. Microbiol. Rev., 21, 262-273. https://doi.org/10.1128/CMR.00026-07.

Brown, H. L., van Vliet, A. H. M., Betts, R. P., \& Reuter, M. (2013). Tetrazolium reduction allows assessment of biofilm formation by Campylobacter jejuni in a food matrix model. J. Appl. Microbiol., 115, 1212-1221. https://doi.org/10.1111/jam.12316.

Butzler, J.-P. (2004). Campylobacter, from obscurity to celebrity. Clin. Microbiol. Infect. Off. Publ. Eur. Soc. Clin. Microbiol. Infect. Dis., 10, 868-876. https://doi.org/10.1111/j.1469-0691.2004.00983.x.

Casagrande Proietti, P., Guelfi, G., Bellucci, S., De Luca, S., Di Gregorio, S., Pieramati, C., et al. (2020). Beta-lactam resistance in Campylobacter coli and Campylobacter jejuni chicken isolates and the association between blaOXA-61 gene expression and the action of $\beta$-lactamase inhibitors. Vet. Microbiol., 241, 108553. https://doi.org/10.1016/j.vetmic.2019.108553.

Chon, J.-W., Hyeon, J.-Y., Choi, I.-S., Park, C.-K., Kim, S.-K., Heo, S., et al. (2011). Comparison of three selective media and validation of the VIDAS Campylobacter assay for the detection of Campylobacter jejuni in ground beef and fresh-cut vegetables. J. Food Prot., 74, 456-460. https://doi.org/10.4315/0362 028X.JFP-10-302.

Chon, J.-W., Kim, H., Yim, J.-H., Park, J.-H., Kim, M.-S., \& Seo, K.-H. (2013) Development of a selective enrichment broth supplemented with bacteriological charcoal and a high concentration of polymyxin B for the detection of Campylobacter jejuni and Campylobacter coli in chicken carcass rinses. Int. J.
Food

Microbiol.,

162

$308-310$

https://doi.org/10.1016/j.ijfoodmicro.2013.01.018.

Colles, F. M., McCarthy, N. D., Sheppard, S. K., Layton, R., \& Maiden, M. C. J (2010). Comparison of Campylobacter populations isolated from a free-range broiler flock before and after slaughter. Int. J. Food Microbiol., 137, 259-264. https://doi.org/10.1016/j.ijfoodmicro.2009.12.021.

Corry, J. E. L., Atabay, H. I., Forsythe, S. J., \& Mansfield, L. P. (2003). Chapter 18 Culture media for the isolation of campylobacters, helicobacters and arcobacters Prog. Ind. Microbiol., 37, 271-316. https://doi.org/10.1016/S00796352(03)80021-8.

Corry, J. E., Post, D. E., Colin, P., and Laisney, M. J. (1995). Culture media for the isolation of campylobacters. Int. J. Food Microbiol., 26, 43-76. https://doi.org/10.1016/0168-1605(95)00044-K.

Couturier, M. R. (2016). Revisiting the Roles of Culture and Culture-Independent Detection Tests for Campylobacter. J. Clin. Microbiol., 54, 1186-1188. https://doi.org/10.1128/JCM.03221-15

Dadar, M., Tiwari, R., Karthik, K., Chakraborty, S., Shahali, Y., and Dhama, K (2018). Candida albicans - Biology, molecular characterization, pathogenicity, and advances in diagnosis and control - An update. Microb. Pathog., 117, 128-138 https://doi.org/10.1016/j.micpath.2018.02.028

Davis, L., \& DiRita, V. (2008). Growth and Laboratory Maintenance of Campylobacter jejuni. Curr. Protoc. Microbiol., CHAPTER 8, Unit-8A.1.7. https://doi.org/10.1002/9780471729259.mc08a01s10.

Dekeyser, P., Gossuin-Detrain, M., Butzler, J. P., and Sternon, J. (1972). Acute enteritis due to related vibrio: first positive stool cultures. J. Infect. Dis., 125, 390 392.

Dingle, K. E., McCarthy, N. D., Cody, A. J., Peto, T. E. A., \& Maiden, M. C. J. (2008). Extended sequence typing of Campylobacter spp., United Kingdom. Emerg. Infect. Dis., 14, 1620-1622. https://doi:10.3201/eid1410.071109.

Duarte, A., Seliwiorstow, T., Miller, W. G., De Zutter, L., Uyttendaele, M., Dierick, K., et al. (2016). Discriminative power of Campylobacter phenotypic and genotypic typing methods. J. Microbiol. Methods., 125, 33-39. 10.1016/j.mimet.2016.03.004.

E, D. G., P, C., G, D. D., L, D., E, G., D, A., et al. (2019). Thermotolerant Campylobacter Spp. In Chicken and Bovine Meat in Italy: Prevalence, Level of Contamination and Molecular Characterization of Isolates. PloS One., 14 https://doi.org/10.1371/journal.pone.0225957.

Efimochkina, N. R., Stetsenko, V. V., Markova, Y. M., Bykova, I. B., Pichugina, T. V., Polyanina, A. S., et al. (2019). [The study of the raw milk contamination by bacteria of the genus Campylobacter using traditional microbiological methods and quantitative PCR assay]. Vopr. Pitan., 88, 17-23. https://doi.org/10.1371/journal.pone.0225957.

Ellington, M. J., Ekelund, O., Aarestrup, F. M., Canton, R., Doumith, M., Giske, C., et al. (2017). The role of whole genome sequencing in antimicrobial susceptibility testing of bacteria: report from the EUCAST Subcommittee. Clin. Microbiol. Infect., 23, 2-22. https://doi.org/10.1016/j.cmi.2016.11.012.

Epps, S. V. R., Harvey, R. B., Hume, M. E., Phillips, T. D., Anderson, R. C., \& Nisbet, D. J. (2013). Foodborne Campylobacter: Infections, Metabolism, Pathogenesis and Reservoirs. Int. J. Environ. Res. Public. Health., 10, 6292-6304 https://doi.org/10.3390/ijerph10126292.

Escher, R., Brunner, C., von Steiger, N., Brodard, I., Droz, S., Abril, C., et al. (2016). Clinical and epidemiological analysis of Campylobacter fetus subsp. fetus infections in humans and comparative genetic analysis with strains isolated from cattle. BMC Infect. Dis., 16. https://doi.org/10.1186/s12879-016-1538-7.

Es-soucratti, K., Hammoumi, A., Bouchrif, B., Asmai, R., En-nassiri, H., \& Karraouan, B. (2020). Occurrence and antimicrobial resistance of Campylobacter jejuni isolates from poultry in Casablanca-Settat, Morocco. Ital. J. Food Saf., 9. https://doi.org/10.4081/ijfs.2020.8692.

European Food Safety Authority, and European Centre for Disease Prevention and Control (2016). The European Union summary report on trends and sources of zoonoses, zoonotic agents and food-borne outbreaks in 2015. EFSA J., 14 https://doi.org/10.2903/j.efsa.2016.4634.

Fitzgerald, C. (2015). Campylobacter. Clin. Lab. Med. 35, 289-298. https://doi.org/10.1016/j.cll.2015.03.001

Florent, A., \& De Keyser, P. (1964). Problems of Infertility in Livestock in Belgium. Br. Vet. J. 120, 407-414. https://doi.org/10.1016/s0007-1935(17)41603$\underline{4}$

Fontanot, M., Iacumin, L., Cecchini, F., Comi, G., \& Manzano, M. (2014). PorA specific primers for the identification of Campylobacter species in food and clinical samples. LWT - Food Sci. Technol., 58, 86-92. https://doi.org/10.1016/j.lwt.2014.03.006.

Frost, J. A., Oza, A. N., Thwaites, R. T., \& Rowe, B. (1998). Serotyping scheme for Campylobacter jejuni and Campylobacter coli based on direct agglutination of heat-stable antigens. J. Clin. Microbiol., 36, 335-339. https://doi.org/10.1128/jcm.36.2.335-339.1998.

Garenaux, A., Lucchetti-Miganeh, C., Barloy-Hubler, F., Ermel, G., Federighi, M. Tresse, O., et al. (2007). Better Understand the Campylobacter Conundrum Parallel Between Campylobacter Jejuni Genome, Sequence Study and 
Physiology.," in New Developments in Food Microbiology Research, ed. M. C. Berger (Nova Publishers), 1-90. https://hal.archives-ouvertes.fr/hal-00453220

Garibyan, L., \& Avashia, N. (2013). Research Techniques Made Simple: Polymerase Chain Reaction (PCR). J. Invest. Dermatol., 133, e6. https://doi.org/10.1038/jid.2013.1.

Gharst, G., Oyarzabal, O. A., \& Hussain, S. K. (2013). Review of current methodologies to isolate and identify Campylobacter spp. from foods. $J$ Microbiol. Methods., 95, 84-92. https://doi.org/10.1016/j.mimet.2013.07.014. Ghatak, S., He, Y., Reed, S., Strobaugh, T., and Irwin, P. (2017). Whole genome sequencing and analysis of Campylobacter coli $\mathrm{YH} 502$ from retail chicken reveals a plasmid-borne type VI secretion system. Genomics Data., 11, 128-131. https://doi.org/10.1016/j.gdata.2017.02.005.

Ghorbanalizadgan, M., Bakhshi, B., Kazemnejad Lili, A., Najar-Peerayeh, S., \& Nikmanesh, B. (2014). A Molecular Survey of Campylobacter jejuni and Campylobacter Coli Virulence and Diversity. Iran. Biomed. J., 18, 158-164. https://doi.org/10.6091/ibj.1359.2014.

Goering, R. V. (2010). Pulsed field gel electrophoresis: a review of application and interpretation in the molecular epidemiology of infectious disease. Infect. Genet Evol. J. Mol. Epidemiol. Evol. Genet. Infect. Dis., 10, 866-875. https://doi.org/10.1016/j.meegid.2010.07.023.

Gosselin-Théberge, M., Taboada, E., \& Guy, R. A. (2016). Evaluation of real-time PCR assays and standard curve optimisation for enhanced accuracy in quantification of Campylobacter environmental water isolates. J. Microbiol. Methods., 129, 70-77. https://doi.org/10.1016/j.mimet.2016.07.025.

Griggs, D. J., Peake, L., Johnson, M. M., Ghori, S., Mott, A., \& Piddock, L. J. V. (2009). Beta-lactamase-mediated beta-lactam resistance in Campylobacte species: prevalence of Cj0299 (bla OXA-61) and evidence for a novel betaLactamase in C. jejuni. Antimicrob. Agents Chemother., 53, 3357-3364 https://doi.org/10.1128/AAC.01655-08.

Guerry, P., Ewing, C. P., Schirm, M., Lorenzo, M., Kelly, J., Pattarini, D., et al. (2006). Changes in flagellin glycosylation affect Campylobacter autoagglutination and virulence. Mol. Microbiol., 60, 299-311. https://doi.org/10.1111/j.13652958.2006.05100.x.

Haines, M. D., Eberle, K. N., McDaniel, C. D., \& Kiess, A. S. (2011). Evaluating 3 gas-delivery systems for culturing Campylobacter jejuni in a microaerophilic environment. Poult. Sci., 90, 2378-2382. https://doi.org/10.3382/ps.2011-01463. Hilbert, F., Scherwitzel, M., Paulsen, P., \& Szostak, M. P. (2010). Survival of Campylobacter jejuni under conditions of atmospheric oxygen tension with the support of Pseudomonas spp. Appl. Environ. Microbiol., 76, 5911-5917. https://doi.org/10.1128/AEM.01532-10.

Huysmans, M. B., Turnidge, J. D., \& Williams, J. H. (1995). Evaluation of API Campy in comparison with conventional methods for identification of thermophilic campylobacters. J. Clin. Microbiol., 33, 3345-3346. https://www.ncbi.nlm.nih.gov/pubmed/8586735.

Imdad, A., Retzer, F., Thomas, L. S., McMillian, M., Garman, K., Rebeiro, P. F., et al. (2018). Impact of Culture-Independent Diagnostic Testing on Recovery of Enteric Bacterial Infections. Clin. Infect. Dis., 66, 1892-1898 https://doi.org/10.1093/cid/cix1128.

Janda, J. M., and Abbott, S. A. (2014). Culture-independent diagnostic testing: have we opened Pandora's box for good? Diagn. Microbiol. Infect. Dis., 80, 171176. https://doi.org/10.1016/j.diagmicrobio.2014.08.001

Joensen, K. G., Kiil, K., Gantzhorn, M. R., Nauerby, B., Engberg, J., Holt, H. M., et al. (2020). Whole-Genome Sequencing to Detect Numerous Campylobacter jejuni Outbreaks and Match Patient Isolates to Sources, Denmark, 2015-2017. Emerg. Infect. Dis., 26, 523-532. https://doi.org/10.3201/eid2603.190947.

Josefsen, M. H., Lübeck, P. S., Aalbaek, B., \& Hoorfar, J. (2003). Preston and ParkSanders protocols adapted for semi-quantitative isolation of thermotoleran Campylobacter from chicken rinse. Int. J. Food Microbiol., 80, 177-183. https://doi.org/10.1016/S0168-1605(02)00151-4.

Keener, K. m., Bashor, M. p., Curtis, P. a., Sheldon, B. w., \& Kathariou, S. (2004) Comprehensive Review of Campylobacter and Poultry Processing. Compr. Rev. Food Sci. Food Saf., 3, 105-116. https://doi.org/10.1111/j.15414337.2004.tb00060.x

Khan, I. U. H., Gannon, V., Loughborough, A., Jokinen, C., Kent, R., Koning, W., et al. (2009). A methods comparison for the isolation and detection of thermophilic Campylobacter in agricultural watersheds. J. Microbiol. Methods., 79, 307-313. https://doi.org/10.1016/j.mimet.2009.09.024.

Kiehlbauch, J. A., Brenner, D. J., Nicholson, M. A., Baker, C. N., Patton, C. M., Steigerwalt, A. G., et al. (1991). Campylobacter butzleri sp. nov. isolated from humans and animals with diarrheal illness. J. Clin. Microbiol., 29, 376-385. https://doi.org/10.1128/jcm.29.2.376-385.1991

Killam, H. A. W., Crowder, J. G., White, A. C., and Edmonds, J. H. (1966) Pericarditis due to vibrio fetus. Am. J. Cardiol., 17, 723-728 https://doi.org/10.1016/0002-9149(66)90412-7.

Kim, J., Oh, E., Banting, G. S., Braithwaite, S., Chui, L., Ashbolt, N. J., et al. (2016). An Improved Culture Method for Selective Isolation of Campylobacter jejuni from Wastewater. Front. Microbiol., 7,1345 https://doi.org/10.3389/fmicb.2016.01345.
Kist, M. (1986). Who discovered Campylobacter jejuni/coli? A review of hitherto disregarded literature. Zentralbl. Bakteriol. Mikrobiol. Hyg., [A] 261, 177-186. https://eurekamag.com/search.php.

Kumar, R., Surendran, P. K., \& Thampuran, N. (2010). Evaluation of culture media for selective enrichment and isolation of Salmonella in seafood. J. AOAC Int., 93 , 1468-1471. https://doi.org/10.1093/jaoac/93.5.1468

Langley, G., Besser, J., Iwamoto, M., Lessa, F. C., Cronquist, A., Skoff, T. H., et al. (2015). Effect of Culture-Independent Diagnostic Tests on Future Emerging Infections Program Surveillance. Emerg. Infect. Dis., 21, 1582-1588. https://doi.org/10.3201/eid2109.150570.

Lastovica, A. J., On, S. L. W., \& Zhang, L. (2014). "The Family Campylobacteraceae," in The Prokaryotes: Deltaproteobacteria and Epsilonproteo bacteria, eds. E. Rosenberg, E. F. DeLong, S. Lory, E. Stackebrandt, and F. Thompson (Berlin, Heidelberg: Springer), 307-335. https://doi.org/10.1007/978-3-642-39044-9 274.

Law, J. W.-F., Ab Mutalib, N.-S., Chan, K.-G., and Lee, L.-H. (2014). Rapid methods for the detection of foodborne bacterial pathogens: principles, applications, advantages and limitations. Front. Microbiol., 5, 770. https://doi.org/10.3389/fmicb.2014.00770.

Law, J. W.-F., Ab Mutalib, N.-S., Chan, K.-G., \& Lee, L.-H. (2015). Rapid methods for the detection of foodborne bacterial pathogens: principles, applications, advantages and limitations. Front. Microbiol., 5. https://doi.org/10.3389/fmicb.2014.00770

Leblanc-Maridor, M., Garénaux, A., Beaudeau, F., Chidaine, B., Seegers, H., Denis, M., et al. (2011). Quantification of Campylobacter spp. in pig feces by direct real-time PCR with an internal control of extraction and amplification. $J$ Microbiol. Methods., 85, 53-61. https://doi.org/10.1016/j.mimet.2011.01.013.

Levy, A. J. (1946). A Gastro-enteritis Outbreak Probably Due to a Bovine Strain of Vibrio. Yale J. Biol. Med., 18, 243-258.1.

Li, Y., Zhang, S., He, M., Zhang, Y., Fu, Y., Liang, H., et al. (2018). Prevalence and Molecular Characterization of Campylobacter spp. Isolated from Patients with Diarrhea in Shunyi, Beijing. Front. Microbiol. 9. https://doi.org/10.3389/fmicb.2018.00052.

Liang, H., Wen, Z., Li, Y., Duan, Y., Gu, Y., \&Zhang, M. (2018). Comparison of the Filtration Culture and Multiple Real-Time PCR Examination for Campylobacter spp. From Stool Specimens in Diarrheal Patients. Front Microbiol., 9. https://doi.org/10.3389/fmicb.2018.02995.

Lindsey, R. L., Pouseele, H., Chen, J. C., Strockbine, N. A., \& Carleton, H. A. (2016). Implementation of Whole Genome Sequencing (WGS) for Identification and Characterization of Shiga Toxin-Producing Escherichia coli (STEC) in the United States. Front. Microbiol., 7. https://doi.org/10.3389/fmicb.2016.00766

Llarena, A.-K., Taboada, E., \& Rossi, M. (2017). Whole-genome sequencing in the epidemiology of Campylobacter jejuni infections. J. Clin. Microbiol., JCM.0001717. https://doi.org/10.1128/JCM.00017-17.

Luechtefeld, N. W., Reller, L. B., Blaser, M. J., \& Wang, W. L. (1982). Comparison of atmospheres of incubation for primary isolation of Campylobacter fetus subsp. jejuni from animal specimens: 5\% oxygen versus candle jar. J. Clin. Microbiol. 15, 53-57. 10.1128/jcm.15.1.53-57.1982.

Lytsy, B., Engstrand, L., Gustafsson, Å., \& Kaden, R. (2017). Time to review the gold standard for genotyping vancomycin-resistant enterococci in epidemiology: Comparing whole-genome sequencing with PFGE and MLST in three suspected outbreaks in Sweden during 2013-2015. Infect. Genet. Evol., 54, 74-80 https://doi.org/10.1016/j.meegid.2017.06.010.

Macé, S., Haddad, N., Zagorec, M., \& Tresse, O. (2015). Influence of measurement and control of microaerobic gaseous atmospheres in methods for Campylobacter growth studies. Food Microbiol., 52, 169-176. https://doi.org/10.1016/j.fm.2015.07.014.

Malhotra-Kumar, S., Abrahantes, J. C., Sabiiti, W., Lammens, C., Vercauteren, G., Ieven, M., et al. (2010). Evaluation of Chromogenic Media for Detection of Methicillin-Resistant Staphylococcus aureus. J. Clin. Microbiol., 48, 1040-1046. https://doi.org/10.1128/JCM.01745-09.

Marder, E. P., Cieslak, P. R., Cronquist, A. B., Dunn, J., Lathrop, S., Rabatsky-Ehr T., et al. (2017). Incidence and Trends of Infections with Pathogens Transmitted Commonly Through Food and the Effect of Increasing Use of Culture-Independent Diagnostic Tests on Surveillance - Foodborne Diseases Active Surveillance Network, 10 U.S. Sites, 2013-2016. MMWR Morb. Mortal. Wkly. Rep., 66, $397-$ 403. http://dx.doi.org/10.15585/mmwr.mm6615a1 external icon

Marshall, B. J., Barrett, L. J., Prakash, C., McCallum, R. W., \& Guerrant, R. L. (1990). Urea protects Helicobacter (Campylobacter) pylori from the bactericidal effect of acid. Gastroenterology., 99, 697-702. https://doi.org/10.1016/00165085(90)90957-3

Martiny, D., Dediste, A., Debruyne, L., Vlaes, L., Haddou, N. B., Vandamme, P., et al. (2011). Accuracy of the API Campy system, the Vitek 2 NeisseriaHaemophilus card and matrix-assisted laser desorption ionization time-of-flight mass spectrometry for the identification of Campylobacter and related organisms. Clin. Microbiol. Infect. Off. Publ. Eur. Soc. Clin. Microbiol. Infect. Dis., 17, 1001 1006. https://doi.org/10.1111/j.1469-0691.2010.03328.x. 
McAdam, A. J. (2017). Unforeseen Consequences: Culture-Independent Diagnostic Tests and Epidemiologic Tracking of Foodborne Pathogens. J. Clin. Microbiol., 55, 1978-1979. https://doi.org/10.1128/JCM.00678-17.

Medicine, C. for V. (2020). FDA. FDA. Available at: https://www.fda.gov/animalveterinary/national-antimicrobial-resistance-monitoring-system/resources

[Accessed June 8, 2020].

Miller, W. G., Parker, C. T., Rubenfield, M., Mendz, G. L., Wösten, M. M. S. M., Ussery, D. W., et al. (2007). The Complete Genome Sequence and Analysis of the Epsilonproteobacterium Arcobacter butzleri. PLOS ONE., 2, e1358. https://doi.org/10.1371/journal.pone.0001358.

Nachamkin, I., and Barbagallo, S. (1990). Culture confirmation of Campylobacter spp. by latex agglutination. J. Clin. Microbiol. 28, 817-818.

Nair, G. B., Bhattacharya, S. K., \& Pal, S. C. (1983). Isolation and characterization of Campylobacter jejuni from acute diarrhoeal cases in Calcutta. Trans. R. Soc. Trop. Med. Hyg., 77, 474-476.

Nakari, U.-M., Puhakka, A., and Siitonen, A. (2008). Correct identification and discrimination between Campylobacter jejuni and C. coli by a standardized hippurate test and species-specific polymerase chain reaction. Eur. J. Clin Microbiol. Infect. Dis. Off. Publ. Eur. Soc. Clin. Microbiol., 27, 513-518. https://doi.org/10.1007/s10096-008-0467-9.

Odongo, R., Reilly, S. S., \& Gilliland, S. E. (2009). Validation of an improved method for detection of Campylobacter jejuni in foods. J. Food Sci., 74, M207212. https://doi.org/10.1111/j.1750-3841.2009.01153.x.

O’Hara, G. A., Fitchett, J. R. A., \& Klein, J. L. (2017). Campylobacter bacteremia in London: A 44-year single-center study. Diagn. Microbiol. Infect. Dis., 10.1016/j.diagmicrobio.2017.05.015.

On, S. L. (1996). Identification methods for campylobacters, helicobacters, and related organisms. Clin. Microbiol. Rev., 9, 405-422.

On, S. L. W. (2001). Taxonomy of Campylobacter, Arcobacter, Helicobacter and related bacteria: current status, future prospects and immediate concerns. J. Appl. Microbiol., 90, 1S-15S. https://doi.org/10.1046/j.1365-2672.2001.01349.x.

On, S. L. W. (2013). Isolation, identification and subtyping of Campylobacter: Where to from here? J. Microbiol. Methods., 95, 3-7. https://doi.org/10.1016/j.mimet.2013.06.011

O'REILLY, L. C., INGLIS, T. J. J., \& UNICOMB, L. (2006). Australian multicentre comparison of subtyping methods for the investigation of Campylobacter infection. Epidemiol. Infect., 134, 768-779. 10.1017/S0950268805005777.

Pacanowski, J., Lalande, V., Lacombe, K., Boudraa, C., Lesprit, P., Legr and, P., et al. (2008). Campylobacter bacteremia: clinical features and factors associated with fatal outcome. Clin. Infect. Dis. Off. Publ. Infect. Dis. Soc. Am., 47, 790-796. 10.1086/591530.

Parker, C. T., Miller, W. G., Horn, S. T., \& Lastovica, A. J. (2007). Common genomic features of Campylobacter jejuni subsp. doylei strains distinguish them from C. jejuni subsp. jejuni. BMC Microbiol., 7, 50. https://doi.org/10.1186/14712180-7-50.

Perry, J. D., \& Freydière, A. M. (2007). The application of chromogenic media in clinical microbiology. J. Appl. Microbiol. 103, 2046-2055. 10.1186/1471-2180-7$\underline{50 .}$

Rahimi, E., Momtaz, H., Ameri, M., Ghasemian-Safaei, H., and Ali-Kasemi, M (2010). Prevalence and antimicrobial resistance of Campylobacter species isolated from chicken carcasses during processing in Iran. Poult. Sci., 89, 1015-1020 https://doi.org/10.3382/ps.2009-00090.

Reina, J., Ros, M. J., \& Serra, A. (1995). Evaluation of the API-campy system in the biochemical identification of hippurate negative campylobacter strains isolated from faeces. J. Clin. Pathol., 48, 683-685.

Repérant, E., Laisney, M. J., Nagard, B., Quesne, S., Rouxel, S., Le Gall, F., et al. (2016). Influence of enrichment and isolation media on the detection of Campylobacter spp. in naturally contaminated chicken samples. J. Microbiol. Methods., 128, 42-47. 10.1016/j.mimet.2016.06.028.

Ricke, S. C., Feye, K. M., Chaney, W. E., Shi, Z., Pavlidis, H., \& Yang, Y. (2019) Developments in Rapid Detection Methods for the Detection of Foodborne Campylobacter in the United States. Front. Microbiol., 9 https://doi.org/10.3389/fmicb.2018.03280.

Sabat, A. J., Budimir, A., Nashev, D., Sá-Leão, R., van Dijl, J. m, Laurent, F., et al (2013). Overview of molecular typing methods for outbreak detection and epidemiological surveillance. Euro Surveill. Bull. Eur. Sur Mal. Transm. Eur. Commun. Dis. Bull., 18, 20380.

Sandstedt, K., Ursing, J., \& Walder, M. (1983). Thermotolerant Campylobacter with no or weak catalase activity isolated from dogs. Curr. Microbiol., 8, 209-213. https://doi.org/10.1007/BF01579548.

Sanger, F., \& Coulson, A. R. (1975). A rapid method for determining sequences in DNA by primed synthesis with DNA polymerase. J. Mol. Biol., 94, 441-448. 10.1016/0022-2836(75)90213-2.

Scharff, R. L., Besser, J., Sharp, D. J., Jones, T. F., Peter, G.-S., \& Hedberg, C. W. (2016). An Economic Evaluation of PulseNet: A Network for Foodborne Disease Surveillance. Am. J. Prev. Med., 50, S66-S73. doi.10.1016/j.amepre.2015.09.018 Sebald, M., Veron, M. (1963). [BASE DNA CONTENT AND CLASSIFICATION OF VIBRIOS]. Ann. Inst. Pasteur., 105, 897-910.
Shea, S., Kubota, K. A., Maguire, H., Gladbach, S., Woron, A., Atkinson-Dunn, R., et al. (2017). Clinical Microbiology Laboratories' Adoption of CultureIndependent Diagnostic Tests Is a Threat to Foodborne-Disease Surveillance in the United States. J. Clin. Microbiol., 55, 10-19. 10.1128/JCM.01624-16.

Silva, N. da, \& Van Dender, P. (2013). Microbiological examination methods of food and water: a laboratory manual. Boca Raton: CRC Press/Taylor Francis Group.

Silva, J., Leite, D., Fernandes, M., Mena, C., Gibbs, P. A., \& Teixeira, P. (2011) Campylobacter spp. as a Foodborne Pathogen: A Review. Front. Microbiol., 2. https://10.3389/fmicb.2011.00200.

Silva, M. F., Pereira, G., Carneiro, C., Hemphill, A., Mateus, L., Lopes-da-Costa L., et al. (2020). Campylobacter portucalensis sp. nov., a new species of Campylobacter isolated from the preputial mucosa of bulls. PLOS ONE., 15, e0227500. https://doi.org/10.1371/journal.pone.0227500.

Singh, H., Rathore, R. S., Singh, S., \& Cheema, P. S. (2011). Comparative Analysis of Cultural Isolation and Pcr Based Assay for Detection of Campylobacter Jejun In Food and Faecal Samples. Braz. J. Microbiol., 42, 181-186. https://doi.org/10.1590/S1517-83822011000100022.

Skirrow, M. B. (2006). John McFadyean and the centenary of the first isolation of Campylobacter species. Clin. Infect. Dis. Off. Publ. Infect. Dis. Soc. Am., 43, 12131217. https://doi.org/10.1086/508201.

Smith, T. (1919). The etiological relation of spirilla (vibrio fetus) to bovine abortion. J. Exp. Med., 30, 313-323.

Smith, T., \& Taylor, M. S. (1919). Some Morphological And Biological Characters Of The Spirilla (Vibrio Fetus, N. Sp.) Associated With Disease Of The Fetal Membranes In Cattle. J. Exp. Med., 30, 299-311.

Steele, T. W., \& McDermott, S. N. (1984). The use of membrane filters applied directly to the surface of agar plates for the isolation of Campylobacter jejuni from feces. Pathology (Phila.)., 16, 263-265.

Szczepanska, B., Andrzejewska, M., Spica, D., and Klawe, J. J. (2017). Prevalence and antimicrobial resistance of Campylobacter jejuni and Campylobacter coli isolated from children and environmental sources in urban and suburban areas. BMC Microbiol., 17. https://doi.org/10.1186/s12866-017-0991-9.

Taboada, E. N., Clark, C. G., Sproston, E. L., \& Carrillo, C. D. (2013). Current methods for molecular typing of Campylobacter species. J. Microbiol. Methods. 95, 24-31. https://doi.org/10.1016/j.mimet.2013.07.007.

Tuuminen, T., Lounamo, K., \& Leirisalo-Repo, M. (2013). A Review of Serological Tests to Assist Diagnosis of Reactive Arthritis: Critical Appraisal on Methodologies. Front. Immunol., 4. https://doi.org/10.3389/fimmu.2013.00418.

Ugarte-Ruiz, M., Wassenaar, T. m., Gómez-Barrero, S., Porrero, M. c., NavarroGonzalez, N., and Domínguez, L. (2013). The effect of different isolation protocols on detection and molecular characterization of Campylobacter from poultry. Lett Appl. Microbiol., 57, 427-435. https://doi.org/10.1111/lam.12130.

Vandamme, P., Falsen, E., Rossau, R., Hoste, B., Segers, P., Tytgat, R., et al. (1991) Revision of Campylobacter, Helicobacter, and Wolinella taxonomy: emendation of generic descriptions and proposal of Arcobacter gen. nov. Int. J. Syst. Bacteriol., 41, 88-103. https://doi.org/10.1099/00207713-41-1-88.

Vinueza-Burgos, C., Wautier, M., Martiny, D., Cisneros, M., Van Damme, I., \& De Zutter, L. (2017). Prevalence, antimicrobial resistance and genetic diversity of Campylobacter coli and Campylobacter jejuni in Ecuadorian broilers at slaughter age. Poult. Sci., https://doi.org/10.3382/ps/pew487.

Wang, W. L., Luechtefeld, N. W., Blaser, M. J., \& Reller, L. B. (1982). Comparison of CampyPak II with standard 5\% oxygen and candle jars for growth of Campylobacter jejuni from human feces. J. Clin. Microbiol., 16, 291-294.

Wang, W. L., Luechtefeld, N. W., Blaser, M. J., \& Reller, L. B. (1983). Effect of incubation atmosphere and temperature on isolation of Campylobacter jejuni from human stools. Can. J. Microbiol., 29, 468-470. 10.1139/m83-075.

Wassenaar, T. M., \& Newell, D. G. (2000). Genotyping of Campylobacter spp. Appl. Environ. Microbiol., 66, 1-9.

Woodward, D. L., \& Rodgers, F. G. (2002). Identification of Campylobacter HeatStable and Heat-Labile Antigens by Combining the Penner and Lior Serotyping Schemes. J. Clin. Microbiol., 40, 741-745. https://doi.org/10.1128/JCM.40.3.741745.2002

Yadav, R., Yadav, J., Maherchandani, S., \& Kashyap, S. K. (2018). Typing of Campylobacter jejuni isolated from poultry on the basis of flaA-RFLP by various restriction enzymes. Vet. Anim. Sci., 6, 1-5. https://doi.org/10.1016/j.vas.2018.06.003. 